\title{
REVIEW \\ Genetics and evolution of triatomines: from phylogeny to vector control
}

\begin{abstract}
S Gourbière ${ }^{1,2}$, P Dorn ${ }^{3}$, F Tripet ${ }^{4}$ and E Dumonteil ${ }^{5}$
Triatomines are hemipteran bugs acting as vectors of the protozoan parasite Trypanosoma cruzi. This parasite causes Chagas disease, one of the major parasitic diseases in the Americas. Studies of triatomine genetics and evolution have been particularly useful in the design of rational vector control strategies, and are reviewed here. The phylogeography of several triatomine species is now slowly emerging, and the struggle to reconcile the phenotypic, phylogenetic, ecological and epidemiological species concepts makes for a very dynamic field. Population genetic studies using different markers indicate a wide range of population structures, depending on the triatomine species, ranging from highly fragmented to mobile, interbreeding populations.

Triatomines transmit $T$. cruzi in the context of complex interactions between the insect vectors, their bacterial symbionts and the parasites; however, an integrated view of the significance of these interactions in triatomine biology, evolution and in disease transmission is still lacking. The development of novel genetic markers, together with the ongoing sequencing of the Rhodnius prolixus genome and more integrative studies, will provide key tools to expanding our understanding of these important insect vectors and allow the design of improved vector control strategies.
\end{abstract}

Heredity (2012) 108, 190-202; doi:10.1038/hdy.2011.71; published online 7 September 2011

Keywords: Chagas disease; phylogeny; population genetics; community epidemiology; Trypanosoma

\section{TRIATOMINES AND CHAGAS DISEASE}

Chagas disease is one of the most neglected tropical diseases, named after the Brazilian physician Carlos Chagas who first described it 100 years ago. It is caused by the protozoan kinetoplastid parasite Trypanosoma cruzi, which is transmitted to mammalian hosts primarily by blood-feeding insect vectors of the Reduviidae family. T. cruzi infection affects 9-11 million people, mostly in Latin America, but international migration means it is now a global disease reaching vector-free areas (WHO, 2007; Gurtler et al., 2008; Jackson et al., 2009).

Because of limited therapeutic options, most control efforts have focused on the elimination of triatomine vectors from houses, usually by application of residual insecticides and/or housing improvement (Dias et al., 2002). Research devoted to understanding of triatomine biology, genetics and evolution has supported rational vector control strategies; the latter two are reviewed here.

Triatomines are hemipteran (true) bugs, which go through five nymphal stages before reaching the adult stage. At least one blood meal is required to molt into the next stage. The development from egg to adult lasts 3-6 months depending on the species and feeding frequency, and insects can live from 6 months to 2 years (Beard, 2005). Triatomines become infected when they feed on a mammalian host infected with T. cruzi. The parasites then multiply in the insect's guts and can be transmitted to a new host during a subsequent blood meal when accompanied by defecation of the vector as infective parasites are passed in the feces. The parasite can then enter the mammalian host through microlesions of the skin or through mucous membranes (Beard, 2005).

Some triatomine species have been able to adapt to human housing, becoming domiciliated, and are thus very effective vectors of Chagas disease owing to the extensive contacts with humans. Others have remained more sylvatic (remaining in wild areas), and only occasionally invade houses and may then feed on humans (Beard, 2005).

\section{SYSTEMATICS AND PHYLOGENY}

Most triatomine species (subfamily Triatominae) and 14 of the 15 known genera occur in the New World (Figure 1); one genus is unique to Asia and the genus Triatoma is found both in Asia and America. The evolution and diversification of the Triatominae is thought to have coincided with that of mammals and birds during the Jurassic period (Schofield, 2000, Tartarotti et al. 2006). They belong to the Reduviidae (Heteroptera), a much older family of predatory bugs (already present in the Permian-Triassic period) with a worldwide distribution that feeds on other insects rather than sucking blood (Schofield, 2000). It is believed that the evolution of the Cimicidae blood-sucking bugs in Africa preceded that of Triatominae in America and thus prevented their expansion on the African continent by occupying their potential ecological niche (Tartarotti et al. 2006).

The task of classifying the currently 140 recognized triatomine species and understanding their evolutionary relationships is not

${ }^{1}$ UMR 5244 CNRS-UPVD 'Ecologie et Evolution des Interactions', Université de Perpignan Via Domitia, Perpignan, France; ${ }^{2}$ Centre for the Study of Evolution, School of Life Sciences, University of Sussex, Brighton, UK; ${ }^{3}$ Department of Biological Sciences, Loyola University New Orleans, New Orleans, LA, USA; ${ }^{4}$ Centre for Applied Entomology and Parasitology, Keele University, Newcastle-under-Lyme, UK and ${ }^{5}$ Laboratorio de Parasitología, Centro de Investigaciones Regionales 'Dr Hideyo Noguchi', Universidad Autónoma de Yucatán, Merida, Mexico

Correspondence: Professor E Dumonteil, Laboratorio de Parasitología, Centro de Investigaciones Regionales 'Dr Hideyo Noguch', Universidad Autónoma de Yucatán, Ave. Itzaes \#490 x 59, Mérida 97000, Yucatan, Mexico.

E-mail: oliver@uady.mx

Received 23 February 2011; revised 20 July 2011; accepted 25 July 2011; published online 7 September 2011 


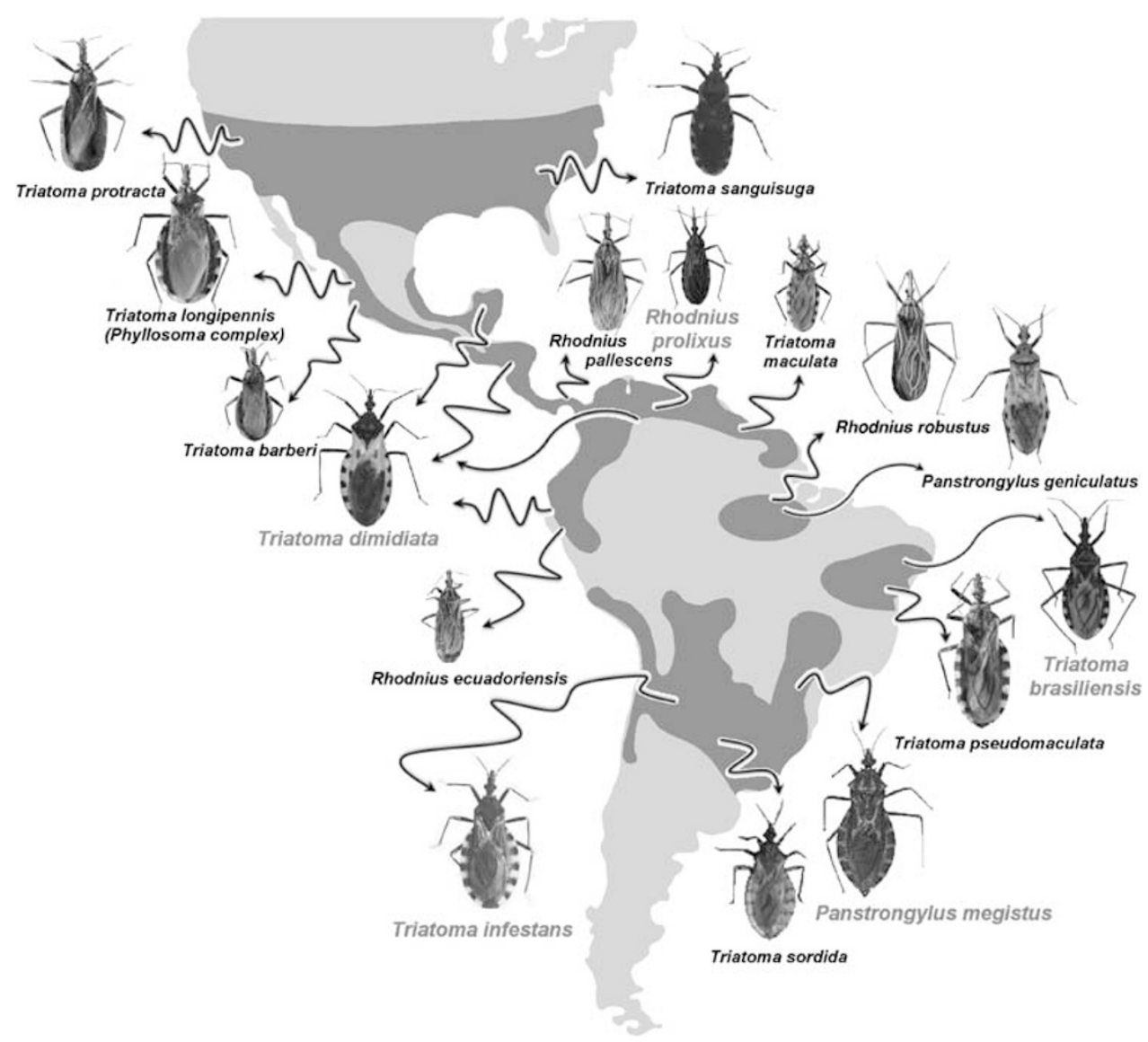

Figure 1 Distribution of triatomine species of major epidemiological relevance. Only about 20 triatomine species are responsible for $T$. cruzi transmission to humans, because of their ability to infest and, for some species, to colonize human habitat. The red areas indicate the approximate species geographic distribution. Species highlighted in red are considered the most important vectors of the parasite.

simple (Schofield and Galvão, 2009). It is important to stress that, because triatomine research is driven by their medical importance, the focus is often on 'epidemiological types' because they are more relevant to Chagas disease epidemiology and vector control than classical taxonomical distinctions. Thus, only about 20 species from the genera Triatoma, Rhodnius and Panstrongylus are particularly relevant for T. cruzi transmission to humans, and most studies focus on these species (Figure 1). Epidemiologically, Triatoma infestans, Triatoma dimidiata, Triatoma brasiliensis, Rhodnius prolixus and Panstrongylus megistus are considered the most important primary vectors. The reconciliation of the phenotypic, phylogenetic and ecological/epidemiological species concepts, and application of distinct methodologies, makes for a very dynamic field of research in medical entomology.

\section{Triatomine species identification: interbreeding, cytotypes and} species complexes

Because of differences in vectorial capacity among triatomine species, their correct taxonomic identification is a first key step for vector surveillance and control programs. The current classification of the Triatominae into five tribes and 15 genera is largely based on morphological characters, including chromatic ones (Lent and Wygodzinsky, 1979). The most commonly used characters are head and wing shape (Dujardin et al., 1999b; dos Santos et al., 2003; Dumonteil et al., 2007), but a number of other characters have been used such as the structure of the male genitalia (Obara et al., 2007), the egg (dos Santos et al., 2009), antenna (Silva et al., 2002; Catala et al., 2005) and rostrum (Silva et al., 2003). Within the triatomines, for example, the monophylly of the Rhodiniini tribe has been supported by apical antenna insertion, body forms, post-ocular callosities, male genital characteristics, egg surface architecture and salivary gland protein composition (Tartarotti et al., 2006).

Morphological characters can distinguish the vast majority of triatomine species (Carbajal de la Fuente et al., 2011). Recently diverged species can sometimes be differentiated (Gurgel-Goncalves et al., 2010) or be remarkably isomorphic, making the detection and description of cryptic taxa difficult (Abad-Franch and Monteiro, 2005; Nouvellet et al., 2011). A good example of the underlying taxonomic structure, which could not be resolved by morphological studies alone, is the Triatoma sordida species complex whose Argentinean, Brazilian and Bolivian member species could only be described thanks to additional tools such as cytogenetics and molecular markers (Dujardin et al., 1999b). Other triatomine species show such high levels of phenotypic plasticity that they were erroneously split into several species. For example, chromatic variants of T. infestans (one of the most important vectors found in Peru, Bolivia, Brazil, Chile, Paraguay, Uruguay and Argentina) were considered a different species (Triatoma melanosoma in Argentina) or variants (a 'dark morph' in Bolivia). However, these 'species' or variants produced fertile offsprings with T. infestans and no difference was found using cytogenetics and 
molecular markers (Noireau et al., 1997; Dujardin et al., 1999a; Monteiro et al., 1999; Bargues et al., 2006). Similarly, revisions are underway in the Phyllosoma complex, which includes important vectors species in Mexico, all of which are interfertile, so also suspected of incorrect species-level designations (Martinez-Ibarra et al., 2009; Martinez-Hernandez et al., 2010).

There are countless examples in which experimental crosses have been used to complement morphological studies when the latter lead to inconclusive results (Perez et al., 1992), and these still have an important role in clarifying the specific and sub-specific status in triatomine species complexes. For example, crosses were instrumental in establishing the specific status of Triatoma pseudomaculata, an important sylvatic vector in Brazil (Corrêa and Espínola, 1964). They also helped in distinguishing Rhodnius prolixus and Rhodnius robustus, the main vectors of Chagas disease in Venezuela, Colombia and some other regions of central America (Galíndez-Giron et al., 1994). As mentioned previously, crosses were important in clarifying taxonomy in the Infestans complex (Abalos, 1948; Franca, 1985; Monteiro et al., 1999), and more recently, the Phyllosoma complex (Martinez-Ibarra et al., 2009; Martinez-Hernandez et al., 2010).

As in the Diptera, cytogenetics has been an essential tool in Triatominae systematics since the early 1900s (Payne, 1909) and is still very much in use in combination with molecular markers (Bargues et al., 2006; dos Santos et al., 2007). An interesting application involves cytogenetics used in combination with crosses to study karyotypic evolution or 're-patterning' (Perez et al., 2005).

Triatomines show high chromosome homogeneity; nearly all have 20 autosomes and most South American species show two sex chromosomes (XY). Secondary fragmentation is thought to have led to the few instances of 2 or $3 \mathrm{X}$-chromosomes $\left(\mathrm{X}_{1} \mathrm{X}_{2} \mathrm{Y}\right.$ and $\left.\mathrm{X}_{1} \mathrm{X}_{2} \mathrm{X}_{3} \mathrm{Y}\right)$ (Perez et al., 1992) found in some Central and North American species (Panzera et al., 2010). Triatomine chromosomes are holocentric (that is, centromeric activity is spread over the entire chromosomal arm) and unlike the large polytenic metacentric chromosomes of the Diptera, which show clear euchromatic banding patterns, they yield very little information in terms of chromosomal polymorphism. Cytogeneticists have concentrated instead on comparing different stages of meiosis between putative species using cbanding staining, which marks constitutive heterochromatin and allows the identification of distinct heterochomatic blocks along chromosomes (Perez et al., 1992).

Cytogenetic comparisons have helped clarify the T. sordida complex of 'isomorphic' species. They highlighted chromosomal differences between the smaller and darker Argentinean populations of T. sordida (previously known as Triatoma garciabesi) and Brazilian populations, as well as between T. sordida and other closely related species of the complex (Panzera et al., 1997).

Interestingly, chromosomes are often marked by intraspecific polymorphism in heterochromatic content (Panzera et al., 1992; Panzera et al., 2004). For example, the Andean populations of T. infestans present a $50 \%$ higher constitutive heterochromatin content than the non-Andean populations. This led to the suggestion that recent colonization of new habitats has been accompanied by genome reduction (Panzera et al., 2004), but intermediate forms have been described in northern Argentina, which complicates phylogeographic interpretation (Monteiro et al., 2010). In recent studies, measurements of haploid genome size have been used to complement c-banding karyotype comparisons (Panzera et al., 2004) or to corroborate molecular data (Bargues et al., 2006).

Cytogenetics also had a crucial role in the ongoing description of T. dimidiata. This species presents morphologically variable populations, but early attempts to delineate geographic boundaries between them failed, and clinal variation was proposed to explain this species' extensive polymorphism (reviewed by Dorn et al., 2007). Later on however, a combination of morphology, cytogenetics and molecular data led to the unambiguous detection of a cryptic taxon and the recognition of the Dimidiata species complex (Marcilla et al., 2001; Panzera et al., 2006; Dorn et al., 2007, 2009).

In the 1980s, isozyme analysis was first applied to population genetic questions of triatomines. Fixed allelic differences characterizing certain sympatric populations were quickly recognized as proof of their reproductive isolation, hence potential specific status. A good example was the 'chance' discovery of two reproductively isolated sylvatic populations of $T$. sordida in a study of genetic divergence between T. sordida and a closely related species, T. guasayana (Noireau et al., 1998). Another fine example was the realization of the close relationship between the small Rhodnius ecuadoriensis and its 'large cousin' R. prolixus from Colombia, which morphological studies of the Rhodnius sub-tribe described as unrelated (Chavez et al., 1999; Dujardin et al., 1999a, b). Isozymes are still used, mostly because of their affordability and have recently helped clarify species complexes such as the Triatoma rubrovaria and the Triatoma maculata complexes, which include several morphologically similar sylvatic vectors distributed throughout Brazil and Northern South-America (dos Santos et al., 2007).

\section{Origin of triatomines: monophyly versus polyphyly}

Since the late 1990s, DNA sequence data have been used to test phylogenetic relationships between putative taxa, complementing morphological studies based on morphology. Morphological and molecular phylogenies are often used to validate one another and they can generate remarkably similar trees particularly at higher taxonomic levels (Weirauch, 2008; Weirauch and Munro, 2009). However, at lower taxonomic levels, the extensive plasticity of some species can result in morphological convergence or divergence, thus complicating taxonomic assignations (Lent and Wygodzinsky, 1979; Dujardin et al., 1999b). This illustrates the importance of using as many characters as possible for robust taxonomies. A recent cladistic analysis of the assassin bugs (Reduviidae), which includes the Triatominae as well as non-hematophagous families, used as many as 162 morphological characters (Weirauch, 2008). DNA sequences are not immune to convergence (homoplasy) and phylogenetic analyses may depend on the number and types of sequence used, the amount of polymorphic sites they include and a variety of assumption about the rates of mutations (insertions, deletions, transitions, transversions), although these can be estimated independently. Importantly, the possibility of introgression may lead to gene phylogenies that do not reflect the species phylogeny. Future phylogenetic analyses are likely to include whole or nearly whole genomes, and thus provide insights into historical hybridization events.

Perhaps the best illustration of the complexity of phylogenetic interpretations is the long-lasting question of monophyly versus polyphyly of the Triatominae. Morphological studies have been unable to establish if, within the Triatominae, the Rhodniini and the Triatomini tribes evolved from one or more than one bloodsucking ancestor, and whether the Rhodnius and Triatoma genera are paraphyletic with respect to other genera of the Triatominae. The initial sequence-based studies could also not clearly reject one or the other hypothesis because of lack of statistical power (Hypsa et al., 2002; Schofield and Galvão, 2009). Nonetheless, they illustrated the potential pitfalls of phylogenies based on sequence data and led to a progressive increase in the number of taxa, sequence data and analytical approaches involved. 
The latest phylogenetic studies of the Triatominae and other Reduviidae combine several nuclear and mitochondrial DNA (mtDNA) sequences, comprise large numbers of taxa and explore extensive parameter spaces by using parsimony, maximum likelihood and Bayesian analyses (Weirauch and Munro, 2009; Patterson and Gaunt, 2010). The resulting trees recover the Triatominae as a monophyletic taxon with good statistical support, particularly from Bayesian and maximum likelihood inferences (Weirauch and Munro, 2009; Patterson and Gaunt 2010).

Additionally, sequence data have been used to clarify taxonomy at different levels. The phylogeny and taxonomy of the Rhodniini tribe, for example, was derived early on from mitochondrial and nuclear sequences (Monteiro et al., 2000). Ribosomal DNA in combination with haploid genome size comparisons was used to clarify the Infestans complex (Bargues et al., 2006). Recent studies based on ribosomal and mitochondrial genes have helped described several putative species and sub-species within the Dimidiata complex (Marcilla et al., 2001; Ramirez et al., 2005; Bargues et al., 2006; Dorn et al., 2007, 2009; Tamay-Segovia et al., 2008).

Sequence data have several other important advantages over other markers. First, they document sequence polymorphisms that can be readily used to develop simple high-throughput PCR diagnostics for discriminating putative taxa, thus greatly facilitating the work with recently diverged isomorphic species group (Pavan and Monteiro, 2007; Herrera-Aguilar et al., 2009). Cryptic species are not common in the Triatominae, however they have been detected in T. dimidiata (Marcilla et al., 2001; Panzera et al., 2006), T. sordida (Noireau et al., 1998; Panzera et al., 2006) and R. robustus (Monteiro et al., 2003). Natural hybrids also occur, for example, between T. infestans and Triatoma platensis, and these appear to remain separated by occupying distinct ecological niches (Abalos, 1948). In the case of T. dimidiata and the cryptic species, decreased hybrid fitness (Herrera-Aguilar et al., 2009) may be what is maintaining the $>5$-million-year separation, as determined using an ITS-2 molecular clock (Bargues et al., 2008). R. robustus was a concern as a possibly epidemiologically important sylvatic species nearly identical in appearance to $R$. prolixus (Monteiro et al., 2003).

Second, when phylogenies are combined with the known age of geological events to build a so-called 'molecular clock', one can match the age of a putative tree branching event with geological events to generate phylogeographic scenarios. These elegant studies (for example, Monteiro et al., 2004; Bargues et al., 2006) further illuminate the ecological and geological context of the Triatominae extensive species radiation in the New World, and which in turn facilitates our understanding of their systematics.

\section{POPULATION GENETICS}

Population genetics has been an important tool in understanding the epidemiology of Chagas disease and in designing effective control methods to reduce local triatomine populations and interrupt transmission. Such studies have provided estimates of the level of genetic diversity present in populations, which are required to predict vector's adaptability (for example, domestication or development of pesticide resistance). Studies of gene flow among populations can help define the geographic coverage needed for successful control, the importance of sylvan populations in house infestation or the sources of reinfestation following insecticide treatment.

\section{Genetic diversity}

$T$. infestans and $R$. prolixus are two of the most medically important vectors, in large part because they are domestic species across most of their ranges. These two species generally show low genetic diversity in natural populations as well as in laboratory colonies, as determined by allozymes (Harry et al., 1992, 1993; Lopez and Moreno, 1995; Dujardin et al., 1998b; Monteiro et al., 2002) and confirmed by mtDNA and nuclear DNA sequence analyses (Table 1). By contrast, populations of $T$. dimidiata and $T$. brasiliensis, both of which are widespread across domestic, peri-domestic and sylvan habitats, generally show higher diversity, although nearby $T$. dimidiata populations in Costa Rica showed a single ITS-2 haplotype (Table 1). Survival in these very diverse habitats, and movement among habitats, may have resulted in distinct selective pressures thus maintaining genetic diversity. Reduced genetic repertoire owing to founder effects during domestication could explain the low genetic diversity in T. infestans and $R$. prolixus (Schofield et al., 1999). However, domestication per se may not be sufficient to reduce genetic diversity as domestic populations showed nearly identical allozyme (Dujardin et al., 1987), or similar or even greater mtDNA diversity (Fitzpatrick et al., 2008; Piccinali et al., 2009) as nearby sylvan populations. Of course sylvan populations may represent feral derivatives of domestic populations (Dujardin et al., 1987). An alternative hypothesis is that low genetic variability reflects rapid and recent expansion owing to passive dispersal (Dujardin et al., 1998a).

A relatively higher genetic diversity in the T. infestans populations in the Bolivian Andes was used to propose this region as the origin of dispersal (based on allozymes (Dujardin et al., 1998a) and cytb

Table 1 DNA sequence population diversity of major triatomine species

\begin{tabular}{|c|c|c|c|c|c|c|}
\hline Region & Species & Marker & No. populations & $\mathrm{n}$ & Haplotype diversity $\mathrm{H}_{d}$ & References \\
\hline \multirow[t]{4}{*}{ Mexico and Central America } & T. dimidiata ${ }^{a}$ & cytb & 12 & 24 & 0.960 & Dorn et al. (2009) \\
\hline & T. dimidiata ss & cytb & 7 & 58 & 0.901 & Blandon-Naranjo et al. (2010) \\
\hline & T. dimidiata & ITS-2 & 93 & 190 & 0.918 & Bargues et al. (2008); Dorn et al. (2009) \\
\hline & T. dimidiata ss & ITS-2 & 7 & 58 & 0 & Blandon-Naranjo et al. (2010) \\
\hline \multirow[t]{5}{*}{ South America } & T. infestans & cytb & 43 & 98 & 0.737 & Monteiro et al. (1999); Giordano et al. (2005) \\
\hline & R. prolixus & cytb & 34 & 551 & 0.518 & Fitzpatrick et al. (2008) \\
\hline & T. brasiliensis ss & cytb & 4 & 361 & 0.905 & Almeida et al. (2008) \\
\hline & T. brasiliensis ${ }^{b}$ & cytb & 17 & 136 & 0.920 & Monteiro et al. (2004) \\
\hline & T. infestans & ITS-2 & 31 & 35 & 0.591 & Bargues et al. (2006) \\
\hline
\end{tabular}

Abbbreviation: ss, sensu stricto.

$H_{\mathrm{d}}=n\left(1-\Sigma \hat{x}_{1}^{2}\right) /(n-1)$, where $n$ is the sample size and $x$ is the frequency of a haplotype (Nei and Tajima, 1981).

aMay include a cryptic species.

bIncludes three proposed species: T. brasiliensis/T. macromelasoma, T. juazeiro and T. melanica. 
sequence (Giordano et al., 2005)). This hypothesis is supported by cytogenetic differences in the Andean as compared with non-Andean T. infestans, DNA sequence differences (ITS-2 (Bargues et al., 2006) and $c y t b$ (Monteiro et al., 1999 and Giordano et al., 2005)), as well as a highly significant $F_{\mathrm{ST}}=0.36$ between populations from the two areas (based on cytb (Giordano et al., 2005)). Recent studies have shown considerable diversity in the Argentinean T. infestans populations as well (cytochrome oxidase sequence (Piccinali et al., 2009)). The speculation is that, perhaps multiple waves of immigration and rapid spread in Argentina, followed by genetic drift in isolated populations, has increased the genetic variability.

\section{Genetic structure of populations}

Vector migration is important for genetic mixing, re-infestation following pesticide treatment, the spread of genetically modified symbionts (Beard et al., 2002) and pesticide resistance genes. Although adults generally fly poorly (for example, Barbu et al., 2010), some species have been known to fly as far as $1 \mathrm{~km}$, and wingless nymphs can walk tens of meters (Núñez, 1987). In addition to this active dispersion, passive dispersion by human activity, and perhaps carriage on animals and birds, is important over longer distances.

Over long distances, most studies show variation among populations consistent with the 'isolation by distance' model (Wright, 1943; Calderón et al., 2004; Pérez de Rosas et al., 2007, 2008; Piccinali et al., 2009; Table 2). At shorter distances, the picture differs among species and localities, and is often affected by pesticide treatment history.

T. infestans populations are generally highly structured as shown by allozyme analyses (Dujardin et al., 1987, 1998a; Brenière et al., 1998) and microsatellite markers (Table 2), as might be expected for a mostly domestic species. Interestingly, in areas where T. infestans has extensive sylvan populations, gene flow was also restricted among these sylvan populations and largely absent between the sylvan and domestic populations (Richer et al., 2007 and Table 2). Recent analysis of genomic (Perez de Rosas et al., 2011) and mtDNA (Torres-Perez et al., 2011) both support the hypothesis of two independent migration events of T. infestans in South America, and confirmed the existence of two distinct lineages.

By contrast, $T$. dimidiata populations show more extensive gene flow among houses within a village as well as among nearby villages in areas where it seasonally enters homes (Dumonteil et al., 2007;
Table 2). Surprisingly, in areas apparently lacking sylvan populations, high levels of migration among houses within a village and nearby villages are inferred by high gene flow (Dorn et al., 2003; Stevens et al., unpublished data; Table 2). A finding of mostly unrelated or distantly related individuals within a house by random amplification of polymorphic DNA-PCR (RAPD-PCR) (Melgar et al., 2007) also supports substantial movement by $T$. dimidiata. $R$. prolixus also shows movement between most sylvan and domestic populations, indicating that sylvan populations can pose a risk for human infection (Fitzpatrick et al., 2008; Table 2).

\section{INTERACTIONS VECTOR-PARASITE-HOST}

The genetics and evolution of diseases vectors are influenced by relationships with their parasites (Schaub, 2006), hosts (Sacks and Kamhawi, 2001), symbionts (Dillon and Dillon, 2004) and with congeneric vectors (Pereira et al., 2006). These relationships are two-way interactions as vectors also have impacts on the other members of these 'vector-borne disease communities'. An integrated view of the significance of these interactions on the genetic and evolution of triatomines is largely unknown, but some bits of the puzzle are being pieced together.

\section{Triatomine-Trypanosoma interactions}

Once ingested during a blood meal, T. cruzi parasites undergo two major transformations in the vector. Trypomastigotes differentiate into the epimastigote stage, to multiply asexually, before differentiating into infectious metacyclic trypomastigotes (Figure 2). Parasite viability, development and multiplication are then influenced by physiological and biochemical interactions with the vector, according to its life stage and location inside the vector (see Azambuja et al., 2005b; Garcia et al., 2007, 2009).

Studies of the molecular interactions between triatomines and T. cruzi remain scarce as compared with other vector-parasite systems as they lie at the intersection between two neglected fields of research: (i) The immune system of hemipterans, less studied than in higher orders of insects (Ursic-Bedoya and Lowenberger, 2007), and (ii) the role of the innate immunity of insects in flagellate infections, less studied than the response to other microbial organisms (Boulanger et al., 2006). Most studies focus on mechanisms involved in the humoral response (but see Garcia et al., 2004 for insights into the cellular response), their genetic basis and, to a lesser extent, their effects on parasite life history

Table 2 Microsatellite subdivision among triatomine populations

\begin{tabular}{|c|c|c|c|c|c|}
\hline Species & No. of loci & $\begin{array}{c}\text { No. insects per } \\
\text { population }\end{array}$ & Geographic distance & $\mathrm{F}_{S T}$ & References \\
\hline \multicolumn{6}{|l|}{ Among villages } \\
\hline T. dimidiata ${ }^{a}$ & 4 & $11-34$ & $<280 \mathrm{~km}$ & 0.0553 & Dumonteil et al. (2007) \\
\hline T. dimidiata & 8 & $28-30$ & $<13 \mathrm{~km}$ & 0.066 & Stevens et al., unpublished data \\
\hline T. infestans & 10 & $19-74$ & $<1464 \mathrm{~km}$ & $\theta=0.135$ & Pérez de Rosas et al. (2007) \\
\hline T. infestans & 10 & 12-99 & $<31 \mathrm{~km}$ & $0.018-0.192$ & Marcet et al. (2008) \\
\hline T. infestans & 10 & $18-70$ & $<220 \mathrm{~km}$ & 0.169 & Pérez de Rosas et al. (2008) \\
\hline T. infestans & 10 & $1-78$ & $<100 \mathrm{~km}$ & 0.06 & Pizarro et al. (2008) \\
\hline \multicolumn{6}{|l|}{ Among ecotopes } \\
\hline T. dimidiata ${ }^{a}$ & 4 & $18-41$ & $\begin{array}{l}\text { Within villages, sylvan/domestic } \\
\text { and peri-domestic }\end{array}$ & $0.0096-0.0455$ & Dumonteil et al. (2007) \\
\hline R. prolixus & $9-10$ & 10-39 & Varied, sylvan/domestic & $0.001-0.2$ & Fitzpatrick et al. (2008) \\
\hline T. infestans & 9 & $6-32$ & $<1.1 \mathrm{~km}$ sylvan/sylvan; sylvan/domestic & $0.0019-0.110 ; 0.026-0.072$ & Richer et al. (2007) \\
\hline
\end{tabular}

a May include a cryptic species. 


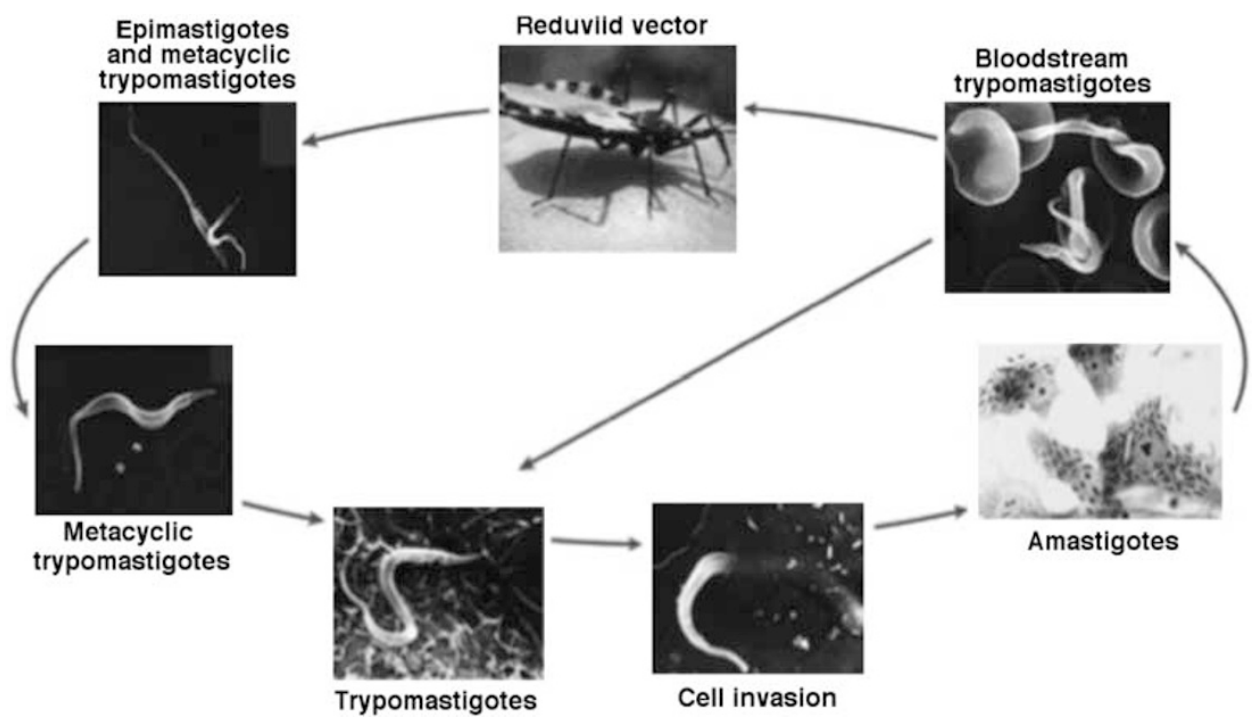

Figure $2 T$. cruzi life cycle. Following a blood meal containing bloodstream trypomastigotes, $T$. cruzi parasites first differentiate into the epimastigote stage and multiply asexually, before differentiating into infectious metacyclic trypomastigotes. Upon entry of trypomastigotes in the mammalian host, those are able to invade cells and further replicate as intracellular amastigotes (from Andrade and Andrews, 2005, with permission).

and within-host dynamics (Table 3). For example, lectins and antimicrobial peptides such as defensins and lysozymes have been described in several triatomine species (Table 3). Many of the corresponding genes are mostly expressed in the stomach (but see Lopez et al., 2003), where symbionts grow intensively after blood meals (Araújo et al., 2006; Balczun et al., 2008). Importantly, defensin is strongly upregulated in the mid-gut of T. brasiliensis following infection with T. cruzi (Waniek et al., 2011). Lysozyme genes are expressed in both the fat body and the mid-gut of triatomines. Trypanolytic factors, the prophenoloxidase cascade and the impact of various oxides have also been studied, but almost exclusively in the hemocel of $R$. prolixus infected by Trypanosoma rangeli.

One of the most intriguing outcomes of triatomines-Trypanosoma interactions is that closely related parasites have very different transmission modes. T. rangeli spreads from the gut to the hemocoel (Mello et al., 1995) and, at least for some (KP1-) populations, to the salivary gland of Rhodnius species, and is transmitted by bites (Guhl and Vallejo, 2003). By contrast, T. cruzi infection is limited to the gut, so that it is transmitted through the vector feces. It is still unclear whether such a difference results from (1) an adaptation of T. cruzi to limit its spread from the gut and avoid the insect immune response primarily located in the hemocoel (Whitten et al., 2001; Lopez et al., 2003), or (2) an adaptation of $T$. rangeli to reduce the impact of the humoral response of the insect, for example, by infecting hemocytes and inhibiting the proPo pathway that leads to melanization (Gregorio and Ratcliffe, 1991; Gomes et al., 1999; Garcia et al., 2007). Interestingly, whereas the first hypothesis involves a trade-off between an increase in T. cruzi growth rate within its vector and a reduced transmission to mammalian hosts, the second hypothesis involves an increase in T. rangeli development rate in the hemolymph, with no detrimental impact on transmission.

There is also evidence that, according to variations in their immune response, vectors are likely to be biological filters transmitting differently lineages/genotypes of T. cruzi and T. rangeli (Vallejo et al., 2009). Lectins produced in the stomach of $R$. prolixus agglutinate Dm28 clones but not the Y-strain of T. cruzi (Mello et al., 1996; Ratcliffe et al., 1996). The presence of trypanolytic factors in the R. prolixus hemolymph impedes the development of $T$. rangeli $\mathrm{KP} 1-$ but not the development of T. rangeli KP1+ (Vallejo et al., 2002, 2003).

The above mechanisms and outcomes of vector-parasite interactions can be thought of in terms of co-evolutionary adaptations, especially within the Rhodnius genus, where T. rangeli is known to be pathogenic to its vector, and where parasite/vector association appear to be more specific (Vallejo et al., 2009). By contrast, a common view is that T. cruzi has little impact on its vector's life history (Zeledón, 1981; Schaub, 1989, 2006; Vallejo et al., 2009), and thus produces no or little selective pressure on its vector. Such a view is supported by a lack of change in developmental time (Zeledón, 1981; Schaub, 1988), life span and fertility (Zeledón, 1981; Schaub, 1989), and feeding behavior (Schaub, 2006; Garcia et al., 2007) when triatomines are infected by $T$. cruzi in the laboratory. But there is counter-evidence (Schaub, 1989, 1994; Botto-Mahan et al., 2006; Botto-Mahan, 2009; Nouvellet et al., 2011) and laboratory experiments often suffer biases, thus weakening their applicability to natural populations (Schaub, 1989). Typically, natural conditions involve long periods of starvation potentially leading to competition for rare nutrients between a vector and its parasites (Kollien and Schaub, 2000). In fact, resistance to starvation decreases after $T$. cruzi infection in both $T$. dimidiata (Vargas and Zeledon, 1985) and T. infestans (Schaub and Lösch, 1989). Nonetheless, as T. cruzi develops in the gut rather than in the hemolymph, it is thought to interfere less with the vector than $T$. rangeli (Lopez et al., 2003; Ursic-Bedoya et al., 2008). However, the mid-gut (and not only the hemocoel) of triatomines has been shown to be immune-reactive, and (artificial) infections of the hemolymph by T. cruzi do induce an immune response (Ursic-Bedoya and Lowenberger, 2007). As T. cruzi is able to enter the hemocoel (Zeledon, 1987; Mello et al., 1995), 'mid-gut habitat preference' observed for T. cruzi, could readily be the outcome of a (potentially costly) immune process preventing the invasion of the hemocoel (Whitten et al., 2001). A detailed understanding of the mechanism blocking the transit of T. cruzi across the mid-gut is thus critically needed to convincingly evaluate the actual cost of T. cruzi infection to the vector.

Overall, although studies of the molecular aspects of the vector immune responses are developing, they still lack quantitative assess- 
Table 3 Components of the humoral response of triatomines

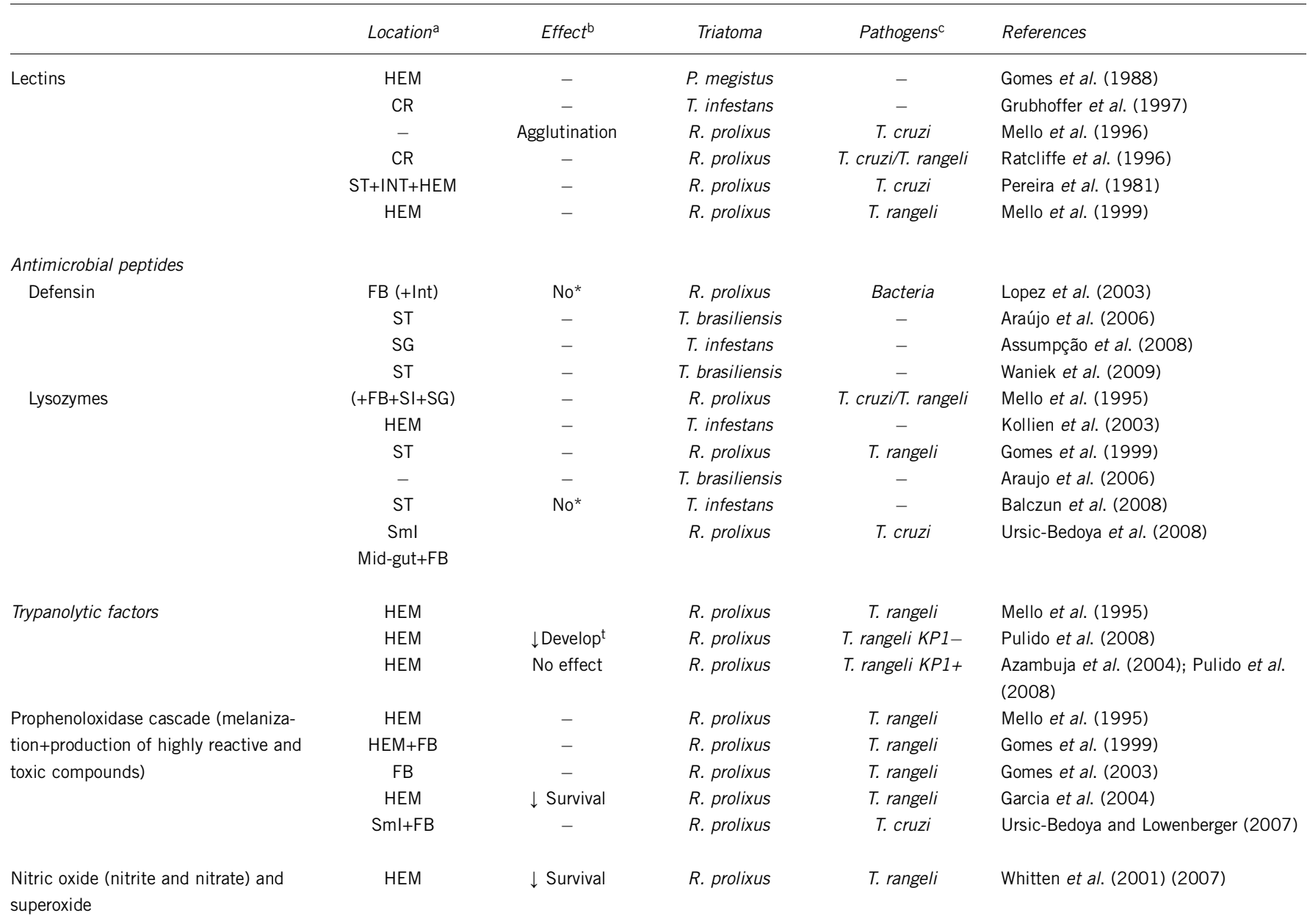

${ }^{a}$ The humoral response has mostly been studied in the hemocoel (HEM) and in the fat body (FB), where it is known to develop in insects. Components of the humoral response have also been studied in the fore-gut, specifically in its last part, the crop (CR), in the mid-gut (both in its anterior, non-digestive part (the cardia (CA) and stomach (ST)) and in its posterior, digestive part (the studied in the fore-gut, specifically in its last part, the crop (CR), in the mid-gut (both in its anterior, non-digestive part (the cardia (CA) and stomach (ST)) and in its posterior, digestive part (the small intestine $(\mathrm{Sml}))$

'Most studies do not test the effect of the molecular mechanism on the parasite life history (denoted by '-'), or speculate that the effect should be minor or null ('No*'). Still, a few experiments have investigated the effects on parasites, which are then specified in the table.

'Some studies include an immunological challenge by a Trypanosoma or bacteria, and this is then specified in the table; others do not include such challenge (denoted by '-').

ments of their effect on parasite life history. Such measurements are critically needed to further understand the mechanisms as well as the evolution of these interactions; especially, the assessment of the effects of T. cruzi under biologically realistic conditions, that is, when infection is considered in synergy with other stress factors such as starvation or co-infection with additional strains. Quantitative assessments would make key contributions to the understanding of the interactions between triatomines and trypanosomes, and ultimately the transmission of Chagas disease.

\section{Triatomine-Trypanosoma-microbiota interactions}

Experimental studies indicate that a community of intestinal microorganisms might regulate the development of parasites in the insect mid-gut (and thus vector competence), although the underlying mechanisms remain largely unknown (Azambuja et al., 2005a). Numerous species of bacteria inhabit the gut of triatomines (listed in Vallejo et al., 2009) and they typically undergo massive population size expansion after a blood meal $\left(10^{2}\right.$ - to $10^{4}$-fold increases; Azambuja et al., 2004), whereas trypanosomes sharply decrease in number
(Azambuja et al., 2005a). The trypanolytic activity of two strains of Serratia marcescens (SM365 and RPH) has been shown recently to be associated with its attachment to the membrane of the T. cruzi Y-strain (Azambuja et al., 2004). The rapid bacterial expansion could then contribute to decreasing parasite abundance in a direct manner. Indirect effects are also expected as increase of bacterial populations activates the production of lysozyme (Kollien et al., 2003) and defensin (Araújo et al., 2006), which are likely to affect the multiplication of trypanosomes. Furthermore, intestinal microorganisms have significant effects on the vectors. Typically, asymbiotic triatomines suffer important developmental delays, and increased mortality (Eichler and Schaub, 2002; Vallejo et al., 2009). A potential explanation is that triatomine blood meals lack essential vitamins and nutrients, which are supplied by symbionts (Beard et al., 2002). Microorganisms may thus influence the vector-parasite interaction through their relationships with both triatomines and trypanosomes. It has indeed been hypothesized that $R$. prolixus has evolved a lower antimicrobial peptide production in the intestine to allow essential symbionts to develop. This could have induced the evolution of a mid- 
gut habitat for T. cruzi (Ursic-Bedoya et al., 2008), leading to the relatively inefficient mode of transmission by feces, with key implications for the triatomine-trypanosome interaction.

\section{Triatomine species interaction}

Studies of interaction between triatomines are rare, and focus on the effect of T. infestans on other Triatominae. T. infestans is thought to have competitively displaced $P$. megistus, T. sordida, T. brasiliensis and T. pseudomaculata from different parts of South America (Figure 1) (Pereira et al., 2006). Such ecological displacement has indeed been observed in laboratory experiments where $T$. infestans consistently excluded T. sordida after a few months (Bar et al., 1994; Oscherov et al., 2001, 2004). Indirect field evidence of competition includes observations of higher house infestation and abundance of T. sordida (Canale et al., 2000; Oscherov et al., 2004), P. megistus (Villela et al., 2005) and T. brasiliensis (Pereira et al., 2006) after removal of T. infestans by control programs. Intraspecific and interspecific competition for blood meals appears to be the key mechanisms to explain such exclusion. In mixed experimental populations, the T. sordida blood-meal size is reduced, leading to lower larval survival rates and reduced population growth, whereas $T$. infestans remains unaffected. Similarly, the competitive advantage of $T$. infestans could result from its ability to ingest larger blood meals, while having a lower requirement to complete its (shorter) life cycle (Pereira et al., 2006). Clearly, interactions between (domestic) T. infestans and (peri-domestic and sylvatic) other triatomine species also involve a dispersal-competitive trade-off (Oscherov et al., 2004), and could thus be better understood if studied in a meta-population dynamic framework such as the ones available for triatomines (Gourbière et al., 2008; Barbu et al., 2009, 2010, 2011; Slimi et al., 2009, and references therein). Understanding the balance between competitive and dispersal abilities will allow understanding the impact of competition between triatomines on parasite transmission, as suggested by theoretical studies (Gourbière and Gourbière, 2002; Begon, 2008).

The interaction between triatomines, their symbionts and trypanosomes establishes a community network with many potential positive and negative feedbacks (Figure 3). In this context, the genetics and evolution of triatomines are likely to follow non-trivial dynamics.
Better knowledge of this complex dynamic will surely be gained by studying the $R$. prolixus $-T$. rangeli and T. infestans $-T$. cruzi interactions, two systems with interesting transmission differences, and by looking at the influence of major triatomine life history on pathogen dynamics (Menu et al., 2010). Additionally, studies of other important vectors of $T$. cruzi and Chagas disease will be needed to reach the general level of understanding required to transfer basic knowledge into safe and efficient control strategies.

\section{VECTOR CONTROL: BEYOND MASSIVE INSECTICIDE SPRAYING}

Most studies of triatomines have been motivated by the need for vector control interventions to prevent Chagas disease transmission to humans. The general aims were thus to identify vector species present in human dwellings, to understand the success or failure of indoor insecticide spraying, as well as to design more rational and evidencebased vector control interventions.

Because the medical entomological importance of vectors was traditionally assumed to be associated with the species, efforts have focused on taxonomic identification, for example, resolving the issue of the sylvatic dark morph of T. infestans (Noireau et al., 1997) and or evaluating gene flow between sylvatic and domestic $R$. robustus and $R$. prolixus in Venezuela, to show that $R$. robustus and $R$. prolixus are distinct species (with rare introgression), and implicating the sylvatic $R$. prolixus populations as potential contributors to human transmission.

T. dimidiata phenotypic variations have also puzzled entomologists for many years, the more so because it was found in a wide variety of habitats, and presented widely different levels of adaptations to human dwellings, ranging from highly domiciliated to preferentially sylvatic (Dorn et al., 2007). The existence of a species complex is now emerging, supported by molecular, morphometric and cytogenetic data (Bustamante et al., 2004; Lehmann et al., 2005; Panzera et al., 2006; Bargues et al., 2008, Dorn et al., 2009), but the association of the different species/subspecies with particular levels of adaptation to the domiciles and vectorial competence is still unclear. For example, two of the distinct $T$. dimidiata cryptic species behave in an identical nondomiciliated manner in the Yucatan peninsula, although one was thought to be much more domiciliated (Dorn et al., 2009; Herrera-

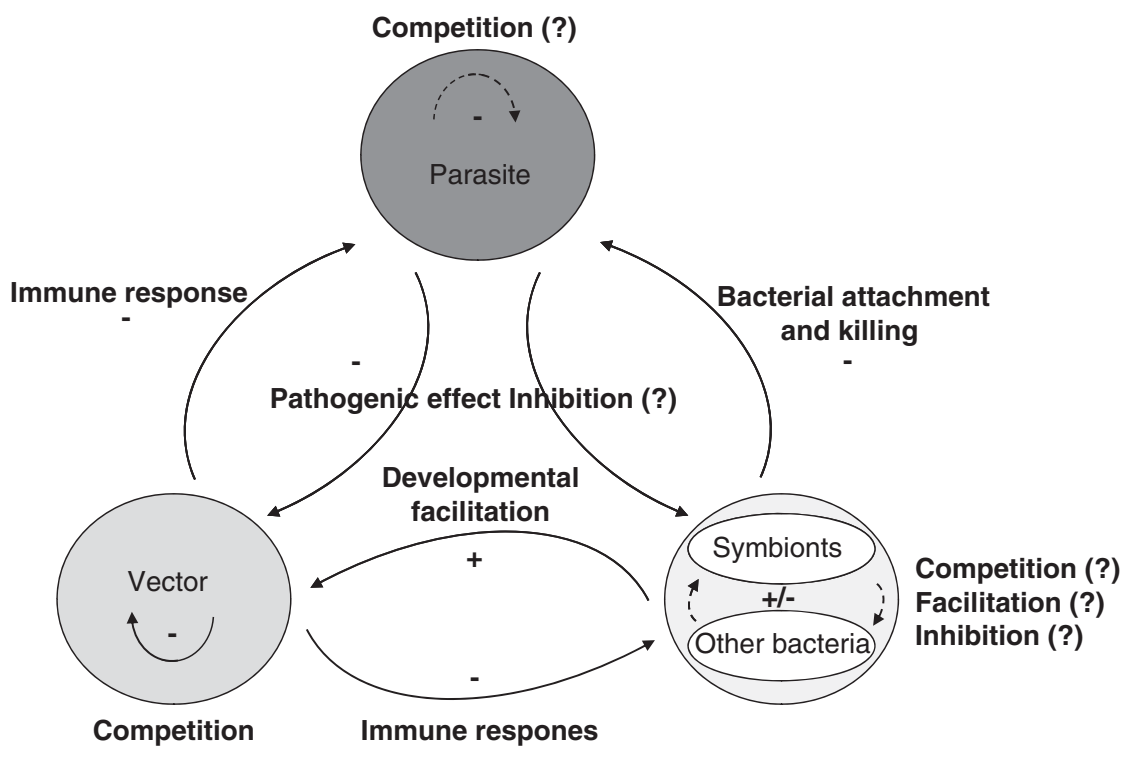

Figure 3 Interaction network. Triatoma, Trypanosoma and microorganisms (either symbiotic or not) interact with one another. Direct or indirect interactions, which have been documented in this review, are all included in this figure. The question marks indicate interactions, which have not yet been investigated. 
Aguilar et al., 2009). This suggests that domiciliation may rather be associated with ecological environments than with species status, which emphasizes the need for more detailed population genetic studies to identify the relevant vector populations.

Indeed, population genetics has been a key tool to define panmictic populations and dispersal range, and thus explain outcomes of vector control efforts. Control strategies based on indoor insecticide spraying began to be tested in the field in the 1940s, and national programs were initiated in the 1970s in several countries such as Brazil, Argentina, Venezuela and Chile, and culminated with several international initiatives such as the Southern Cone or the Central American initiatives in the 1990s (Schofield and Dias, 1999; Dias et al., 2002).

The success of such interventions, which resulted in a $>90 \%$ reduction of house infestation by triatomines and a similar reduction in vectorial transmission of T. cruzi to humans in most of the southern cone region (Dias et al., 2002; Schofield et al., 2006), relied mostly on the marked genetic structure of T. infestans populations and the lack of gene flow among them. However, the elimination of $T$. infestans from houses opened the way for secondary species to start invading this habitat, but again, little is known about triatomine inter-species competition.

As expected, a reduction in the genetic diversity of triatomine populations has been observed following pesticide application, presumably as a result of severe bottlenecks (Garcia et al., 2003). However, some studies have reported an unchanged or even greater genetic diversity after insecticide spraying (Pérez de Rosas et al., 2007, 2008). The authors speculate that the split of a population into several ones, each with different combination of alleles, followed by genetic drift and population expansion could retain the diversity. The effects of anthropogenic changes such as deforestation and global climate change are yet unknown, although the Amazon is becoming a new area for Chagas transmission, coincident with massive deforestation (Diotaiuti, 2009).

In the Gran Chaco region (which encompasses Northern Argentina and parts of Bolivia and Paraguay; Figure 1), vector control measures have notoriously failed. Insects present some months after pesticide treatment are nearly always survivors or migrants from nearby peridomestic populations as revealed by allozyme, mtDNA and microsatellite analyses (Dujardin et al., 1996; Garcia et al., 2003; Perez de Rosas et al., 2007; Pizarro et al., 2008). Heterogeneity in peri-domestic environments (from wood piles to granaries to animal corrals) makes control very difficult (Zu Dohna et al., 2007). In addition, pesticide resistance has now been detected in several of these populations (Gonzalez Audino et al., 2004; Picollo et al., 2005; Toloza et al., 2008, Germano et al., 2010a; Lardeux et al., 2010). The molecular mechanisms of resistance evolved by triatomines may rely on various detoxification pathways (Orihuela et al., 2008). Recent crossing experiments indicate that deltamethrin resistance inheritance is autosomal and semi-dominant, and seems to involve up to three different genes (Cardozo et al., 2010; Germano et al., 2010b). However, more studies are required to further understand the development of insecticide resistance in these species.

When triatomine populations are present in domestic, peri-domestic and sylvatic ecotopes, and gene flow among ecotopes is significant, insecticide spraying is of limited efficacy (Dumonteil et al., 2004; Barbu et al., 2009), likely because populations can be rapidly rebuilt by migrants. Thus, the control of such non-domiciliated or autochthonous triatomines remains a major problem for vector control (Guhl et al., 2009), and novel approaches such as screens, bednets and house improvements will be necessary to interrupt transmission (Figure 4) (Monroy et al., 1998, 2009; Barbu et al., 2009, 2011; Ferral et al., 2010).

Another potential alternative is to manipulate the vector-parasite interaction and modified vector symbionts may allow reducing the parasite transmission rate. For example, Rhodococcus rhodnii can be transformed so that it produces peptides of Lepidoptera (Beard et al., 1998; Beard et al., 2002) or a mammalian antibody (Durvasula et al., 1999) that strongly reduces the number of T. cruzi parasites in the vector. This parasite control strategy has been referred to as paratransgenesis, and may provide new options for Chagas disease control.

Overall, much integration is still needed to take advantage of the genetic and molecular knowledge available to move from the empirical insecticide spraying strategies to the design of more rational and evidence-based control interventions against triatomines. The examples detailed above illustrate how vector control can benefit from genetic studies, and point to gaps in our current understanding of some of these aspects.

\section{CONCLUDING REMARKS}

An increasing number of genetic studies have contributed significantly to our understanding of triatomine biology, from species identification to phylogeny and phylogeography and population genetics. However, a major drawback of many of these studies is that they do not address aspects of the vectorial capacity of the different populations/species (Mas-Coma and Bargues, 2009), making interpretation
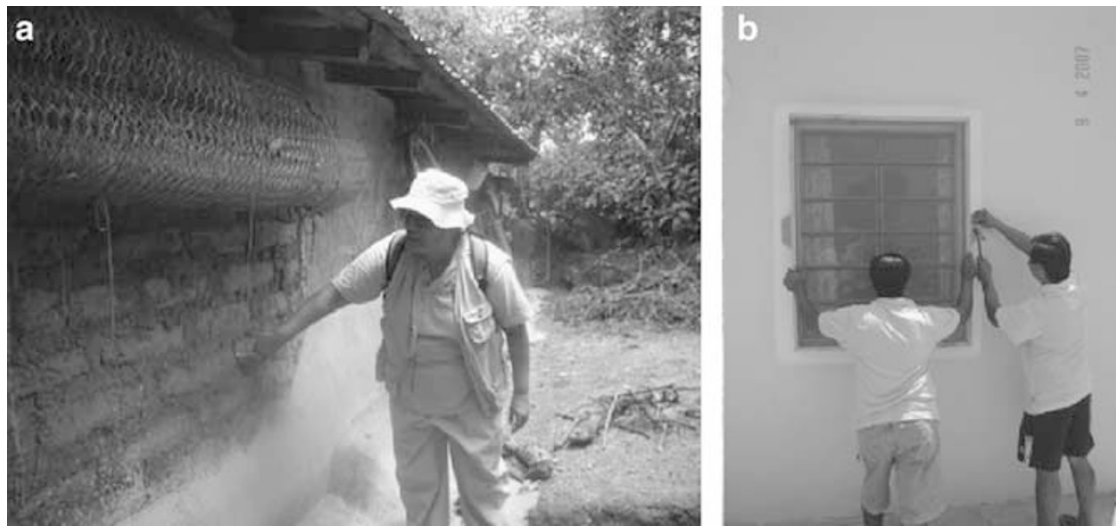

Figure 4 Innovative vector control interventions. Novel interventions, based on detailed knowledge of triatomine species population dynamics and genetics, may rely on improving wall plastering of houses using traditional methods, which prevents colonization (a), or on the installation of insect screens on windows, to prevent transient infestation (b). 
of their results in terms of parasite transmission and epidemiological relevance very speculative. Integrative studies including aspects such as T. cruzi infection rates, blood meal analysis or vector-parasite interactions with population genetic data are thus critically needed to clearly understand the links between population structure and parasite transmission. Such studies would also allow a better understanding of major processes such as the transition from predatory to hematophagous bugs, the domiciliation of triatomines or the impact of control interventions on vectorial transmission.

Whereas several microsatellite markers have been identified in major triatomine species such as $T$. infestans, $T$. dimidiata or $R$. prolixus, molecular markers are lacking for many other species. Also, genome-wide single-nucleotide polymorphism genotyping approaches, which are now popular in other insect vector species (Megy et al., 2009; Horton et al., 2010; Li et al., 2010), have not yet been developed in triatomines. In that respect, the ongoing sequencing of the $R$. prolixus genome (Megy et al., 2009) will provide a very valuable tool to further understand triatomine biology and genetics. Nonetheless, additional triatomine genomes will be required, particularly from the Triatoma genus, and major vector species such as T. infestans or T. dimidiata would be excellent candidates for future genome sequencing. Triatomine genomes would also open the way to extensive studies of vector-parasite interactions at the molecular level, an area where little is known, in spite of the uniqueness of the mechanism of $T$. cruzi transmission through insect feces. Thus, although triatomine genetics research has lagged somewhat compared with other insect species, these species represent unique models for key biological processes, and we can expect that several novel approaches will be developed in the near future to expand our understanding of $T$. cruzi vectorial transmission, vector-parasite interactions and the development of rational vector control strategies.

\section{CONFLICT OF INTEREST}

The authors declare no conflict of interest.

\section{ACKNOWLEDGEMENTS}

This work has been supported in part by Grant no. 2005-1-13790 from CONACYT-SALUD, by the UNDP/World Bank/WHO Special Program for Research and Training in Tropical Diseases (TDR)/International Development Research Center (IDRC), Project no. A90276, by the National Institutes of Health (USA) Grant 1R15 A1079672-01A1, and by EU-FP7-PEOPLE-IntraEuropean Fellowship for career development (IEF) grant no. 253483.

Abad-Franch F, Monteiro F (2005). Molecular research and the control of Chagas disease vectors. An Acad Bras Cienc 77: 437-454.

Abalos JW (1948). Sobre híbridos naturales y experimentales de Triatoma. Anales Inst Medicina Regional 2: 209-223.

Almeida CE, Pacheco RS, Haag K, Dupas S, Dotson EM, Costa J (2008). Inferring from the Cyt B gene the Triatoma brasiliensis Neiva, 1911 (Hemiptera: Reduviidae: Triatominae) genetic structure and domiciliary infestation in the state of Paraiba, Brazil. Am J Trop Med Hyg 78: 791-802.

Almeida CE, Vinhaes MC, Almeida JR, Silveira AC, Costa J (2000). Monitoring the domiciliary and peridomiciliary invasion process of Triatoma rubrovaria in the state of Rio Grande do Sul, Brazil. Mem Inst Oswaldo Cruz 95: 761-768.

Andrade LO, Andrews NW (2005). The Trypanosoma cruzi-host-cell interplay: location, invasion, retention. Nat Rev Microbiol 3: 819-823.

Araújo CAC, Waniek PJ, Stock P, Mayer C, Jansen AM, Schaub GA (2006). Sequence characterization and expression patterns of defensin and lysozyme encoding genes from the gut of the reduviid bug, Triatoma brasiliensis. Insect Biochem $\mathrm{Mol}$ Biol 36: 547-560.

Assumpção TC, Francischetti IM, Andersen JF, Schwarz A, Santana JM, Ribeiro JM (2008). An insight into the sialome of the blood-sucking bug Triatoma infestans, a vector of Chagas disease. Insect Biochem Mol Biol 38: 213-232.
Azambuja P, Feder D, Garcia ES (2004). Isolation of Serratia marcescens in the midgut of Rhodnius prolixus: impact on the establishment of the parasite, Trypanosoma cruzi, in the vector. Exp Parasitol 107: 89-96.

Azambuja P, Garcia ES, Ratcliffe NA (2005a). Gut microbiota and parasite transmission by insect vectors. Trends Parasitol 21: 568-572.

Azambuja P, Ratcliffe NA, Garcia ES (2005b). Towards an understanding of the interactions of Trypanosoma cruzi and Trypanosoma rangeli within the reduviid insect host Rhodnius prolixus. An Acad Bras Cienc 77: 397-404.

Balczun C, Knorr E, Topal H, Meiser CK, Kollien AH, Schaub GA (2008). Sequence characterization of an unusual lysozyme gene expressed in the intestinal tract of the reduviid bug Triatoma infestans (Insecta). Parasitol Res 102: 229-232.

Bar ME, Oscherov EB, Damborsky MP, Porcel EA, Alvarez BM (1994). Population interactions between Triatoma infestans and Triatoma sordida. Rev Saude Publica 28: 59-68.

Barbu C, Dumonteil E, Gourbière S (2009). Optimization of control strategies for nondomiciliated Triatoma dimidiata, Chagas disease vector in the Yucatán peninsula, Mexico. PLoS Negl Trop Dis 3: e416.

Barbu C, Dumonteil E, Gourbière S (2010). Characterization of the dispersal of nondomiciliated Triatoma dimidiata through the selection of spatially explicit models. PLoS Negl Trop Dis 4: e777.

Barbu C, Dumonteil E, Gourbière S (2011). Optimization of spatially targeted vector control interventions for non-domiciliated triatomines. PLoS Neg/ Trop Dis 5: e1045.

Bargues MD, Klisiowicz DR, Gonzalez-Candelas F, Ramsey J, Monroy C, Ponce C et al. (2008). Phylogeography and genetic variations of Triatoma dimidiata, the main Chagas disease vector in Central America, and its position within the genus Triatoma. PLoS Neg/ Trop Dis 2: e233.

Bargues MD, Klisiowicz DR, Panzera F, Noireau F, Marcilla A, Perez R et al. (2006). Origin and phylogeography of the Chagas disease main vector Triatoma infestans based on nuclear rDNA sequences and genome size. Infect Genet Evol 6: 46-62.

Beard CB (2005). Kissing bugs and bedbugs, the heteroptera. In: Marquardt WC (ed). Biology of Disease Vector. Elsevier Academic Press: Amsterdam. pp 57-65.

Beard CB, Cordon-Rosales C, Durvasula RV (2002). Bacterial symbionts of the triatominae and their potential use in control of Chagas disease transmission. Annu Rev Entomol 47: 123-141.

Beard CB, Durvasula RV, Richards FF (1998). Bacterial symbiosis in arthopods and the control of disease transmission. Emerg Infect Dis 4: 581-591.

Begon M (2008). Effects of host diversity on disease dynamics. In: Ostfeld RS, Keesing F, Eviner VT (eds). Infectious Disease Ecology - The Effects of Ecosystems on Disease and of Disease on Ecosystems. Princeton University Press: Princeton, United Kingdom. pp 12-29.

Blandon-Naranjo M, Zuriaga MA, Azofeifa G, Zeledon R, Bargues MD (2010). Molecular evidence of intraspecific variability in different habitat-related populations of Triatoma dimidiata (Hemiptera: Reduviidae) from Costa Rica. Parasitol Res 106: 895-905.

Botto-Mahan C (2009). Trypanosoma cruzi induces life-history trait changes in the wild kissing bug Mepraia spinolai: implications for parasite transmission. Vector Borne Zoonotic Dis 9: 505-510.

Botto-Mahan C, Cattan PE, Medel R (2006). Chagas disease parasite induces behavioural changes in the kissing bug Mepraia spinolai. Acta Trop 98: 219-223.

Boulanger N, Bulet P, Lowenberger C (2006). Antimocrobial peptides in the interaction between insects and flagellate parasites. Trends Parasitol 22: 262-268.

Breniere SF, Bosseno MF, Vargas F, Yaksic N, Noireau F, Noel S et al. (1998). Smallness of the panmictic unit of Triatoma infestans (Hemiptera: Reduviidae). J Med Entomol 35: 911-917.

Bustamante DM, Monroy C, Menes M, Rodas A, Salazar-Schettino PM, Rojas G et al. (2004). Metric variation among geographic populations of the Chagas vector Triatoma dimidiata (Hemiptera: Reduviidae: Triatominae) and related species. J Med Entomol 41: 296-301.

Calderón C, Dorn P, Melgar S, Chávez J, Rodas A, Rosales R et al. (2004). A preliminary assessment of genetic differentiation of Triatoma dimidiata (Hemiptera: Reduviidae) in Guatemala by RAPD-PCR. J Med Entomol 41: 882-887.

Canale DM, Cecere MC, Chuit R, Gürtler RE (2000). Peridomestic distribution of Triatoma garciabesi and Triatoma guasayana in north-west Argentina. Med Vet Entomol 14: 383-390.

Carbajal de la Fuente AL, Jaramillo N, Barata JM, Noireau F, Diotaiuti L (2011). Misidentification of two Brazilian triatomes, Triatoma arthurneivai and Triatoma wygodzinskyi, revealed by geometric morphometrics. Med Vet Entomol 178-183.

Cardozo RM, Panzera F, Gentile AG, Segura MA, Perez R, Diaz RA et al. (2010). Inheritance of resistance to pyrethroids in Triatoma infestans, the main Chagas disease vector in South America. Infect Genet Evol 10: 1174-1178.

Catala S, Sachetto C, Rosales R, Salazar-Schetrino PM, Gorla D (2005). Antennal phenotype of Triatoma dimidiata populations and its relationship with species of phyllosoma and protracta complexes. J Med Entomol 42: 719-725.

Chavez T, Moreno J, Dujardin JP (1999). Isoenzyme electrophoresis of Rhodnius species: a phenetic approach to relationships within the genus. Ann Trop Med Parasitol 93: 299-307.

Corrêa RR, Espínola H (1964). Descrição de Triatoma maculata, nova espécie de triatomíneo de Sobral, Ceará (Hemiptera, Reduviidae). Arq Hig Saúde Púb/ 29: 115-127.

Dias JC, Silveira AC, Schofield CJ (2002). The impact of Chagas disease control in Latin America: a review. Mem Inst Oswaldo Cruz 97: 603-612.

Dillon RJ, Dillon VM (2004). The gut bacteria of insects: nonpathogenic interactions. Annu Rev Entomol 49: 71-92. 
Diotaiuti L (2009). Chapter 4: triatomines vectors of Trypanosoma cruzi infections. In: Teixeira AR, Vinaud M, Castro AM (eds). Emerging Chagas Disease. Bentham Science Publishers Ltd.: Sharjah, UAE, pp 24-39.

Dorn PL, Calderon C, Melgar S, Moguel B, Solorzano E, Dumonteil E et al. (2009). Two distinct Triatoma dimidiata (Latreille, 1811) taxa are found in sympatry in Guatemala and Mexico. PLoS Neg/ Trop Dis 3: e393.

Dorn PL, Melgar S, Rouzier V, Gutierrez A, Combe C., Rosales R. et al. (2003). The Chagas vector, Triatoma dimidiata (Hemiptera: Reduviidae), is panmictic within and among adjacent villages in Guatemala. J Med Entomol 40: 436-440.

Dorn PL, Monroy C, Curtis A (2007). Triatoma dimidiata (Latreille, 1811): a review of its diversity across its geographic range and the relationship among populations. Infect Genet Evol 7: 343-352.

dos Santos CM, Jurberg J, Galvão C, da Rosa JA, Júnior WC, Barata JMS et al. (2009). Comparative descriptions of eggs from three species of Rhodnius (Hemiptera: Reduviidae: Triatominae). Mem Inst Oswaldo Cruz 104: 1012-1018.

dos Santos CM, Jurberg J, Galvão C, Rocha Dda, Fernandez JI (2003). Morphometric study of the genus Panstrongylus Berg, 1879 (Hemiptera, Reduviidae, Triatominae). Mem Inst Oswaldo Cruz 98: 939-944.

dos Santos SM, Lopes CM, Dujardin JP, Panzera F, Pérez R, Carbajal de la Fuente AL et al. (2007). Evolutionary relationships based on genetic and phenetic characters between Triatoma maculata, Triatoma pseudomaculata and morphologically related species (Reduviidae: Triatominae). Infect Genet Evol 7: 469-475.

Dujardin JP, Cardozo L, Schofield C (1996). Genetic analysis of Triatoma infestans following insecticidal control interventions in central Bolivia. Acta Trop 61: 263-266.

Dujardin JP, Chavez T, Moreno JM, Machane M, Noireau F, Schofield CJ (1999a). Comparison of isoenzyme electrophoresis and morphometric analysis for phylogenetic reconstruction of the Rhodniini (Hemiptera: Reduviidae: Triatominae). J Med Entomol 36: 653-659.

Dujardin JP, Munoz M, Chavez T, Ponce C, Moreno J, Schofield CH et al. (1998b). The origin of Rhodnius prolixus in Central America. Med Vet Entomol 12: 113-115.

Dujardin JP, Panzera P., Schofield CJ (1999b). Triatominae as a model of morphological plasticity under ecological pressure. Mem Inst Oswaldo Cruz 94(Suppl 1): 223-228.

Dujardin JP, Schofield CJ, Tibayrenc M (1998a). Population structure of Andean Triatoma infestans: allozyme frequencies and their epidemiological relevance. Med Vet Entomol 12: $20-29$

Dujardin JP, Tibayrenc M, Venegas E, Maldonado L, Desjeux P, Ayala FJ (1987). Isozyme evidence of lack of speciation between wild and domestic Triatoma infestans (Heteroptera: Reduviidae) in Bolivia. J Med Entomol 24: 40-45.

Dumonteil E, Ruiz-Pina H, Rodriguez-Felix E, Barrera-Perez M, Ramirez-Sierra MJ, Rabinovich JE et al. (2004). Re-infestation of houses by Triatoma dimidiata after intra-domicile insecticide application in the Yucatan peninsula, Mexico. Mem Inst Oswaldo Cruz 99: 253-256.

Dumonteil E, Tripet F, Ramirez-Sierra MJ, Payet V, Lanzaro G, Menu F (2007). Assessment of Triatoma dimidiata dispersal in the Yucatan Peninsula of Mexico by morphometry and microsatellite markers. Am J Trop Med Hyg 76: 930-937.

Durvasula RV, Gumbs A, Panackal A, Kruglov O, Taneja J, Kang AS et al. (1999). Expression of a functional antibody fragment in the gut of Rhodnius prolixus via transgenic bacterial symbiont Rhodococcus rhodnii. Med Vet Entomol 13: 115-119.

Eichler S, Schaub GA (2002). Development of symbionts in triatomine bugs and the effects of infections with trypanosomatids. Exp Parasitol 100: 17-27.

Ferral J, Chavez-Nuñez L, Euan-Garcia M, Ramirez-Sierra MJ, Najera-Vasquez MR, Dumonteil E (2010). Comparative field trial of alternative vector control strategies for non-domiciliated Triatoma dimidiata in the Yucatan peninsula, Mexico. Am J Trop Med Hyg 82: 60-66.

Fitzpatrick S, Feliciangeli MD, Sanchez-Martin MJ, Monteiro FA, Miles MA (2008). Molecular genetics reveal that silvatic Rhodnius prolixus do colonise rural houses. PLoS Negl Trop Dis 2: e210.

Franca M (1985) In: Carcavallo RV, Tonn RJ (eds). Vectors in Uruguay. Factores Biologicos y Ecologicos en la Enfermedad de Chagas. Ministerio de Salud, Buenos Aires. pp 457-463.

Galíndez-Giron I, Barazarte R, Márquez J, Oviedo M, Márquez Y, Morón L et al. (1994). Relaciones reproductivas entre Rhodnius prolixus Stal y Rhodnius robustus Larrousse (Hemiptera, Reduviidae, Triatominae) bajo condiciones de laboratorio. Entomol Vect $\mathbf{1}$ : 3-13.

Garcia ES, Castro DP, Figueiredo MB, Genta FA, Azambuja P (2009). Trypanosoma rangeli: a new perspective for studying the modulation of immune reactions of Rhodnius prolixus. Parasit Vect 2: 33.

Garcia ES, Machado EM, Azambuja P (2004). Effects of eicosanoid biosynthesis inhibitors on the prophenoloxidase-activating system and microaggregation reactions in the hemolymph of Rhodnius prolixus infected with Trypanosoma rangeli. J. Insect Physiol 50: 157-165.

Garcia BA, Manfredi C, Fichera L, Segura EL (2003). Short report: variation in mitochondrial $12 \mathrm{~S}$ and $16 \mathrm{~S}$ ribosomal DNA sequences in natural populations of Triatoma infestans (Hemiptera: Reduviidae). Am J Trop Med Hyg 68: 692-694.

Garcia ES, Ratcliffe NA, Whitten MM, Gonzalez MS, Azambuja P (2007). Exploring the role of insect host factors in the dynamics of Trypanosoma cruzi-Rhodnius prolixus interactions. J Insect Physiol 53: 11-21.

Germano MD, Roca Acevedo G, Mougabure Cueto GA, Toloza AC, Vassena CV, Picollo MI (2010a). New findings of insecticide resistance in Triatoma infestans (Heteroptera: Reduviidae) from the Gran Chaco. J Med Entomol 47: 1077-1081.

Germano MD, Vassena CV, Picollo MI (2010b). Autosomal inheritance of deltamethrin resistance in field populations of Triatoma infestans (Heteroptera: Reduviidae) from Argentina. Pest Manag Sci 66: 705-708.
Giordano R, Cortez JC, Paulk S, Stevens L (2005). Genetic diversity of Triatoma infestans (Hemiptera: Reduviidae) in Chuquisaca, Bolivia based on the mitochondrial cytochrome b gene. Mem Inst Oswaldo Cruz 100: 753-760.

Gomes SA, Feder D, Garcia ES, Azambuja P (2003). Suppression of the prophenoloxidase system in Rhodnius prolixus orally infected with Trypanosoma rangeli. J Insect Physiol 49: 829-837.

Gomes SA, Feder D, Thomas NE, Garcia ES, Azambuja P (1999). Rhodnius prolixus infected with Trypanosoma rangeli: in vivo and in vitro experiments. J Invertebr Pathol 73: 289-293.

Gomes YM, Furtado AF, De Carvalho AB (1988). Natural lectin activity in the haemolymph of Panstrongylus megistus (Heteroptera: Reduviidae). Mem Inst Oswaldo Cruz 83: 509-512.

Gourbière S, Dumonteil E, Rabinovich JE, Minkoué R, Menu F (2008). Demographic and dispersal constraints for domestic infestation by non-domicilated Chagas disease vectors in the Yucatan peninsula, Mexico. Am J Trop Med Hyg 78: 133-139.

Gourbière S, Gourbière F (2002). Competition between unit-restricted fungi: a metapopulation model. J Theor Biol 217: 351-368.

Gonzalez Audino P, Vassena C, Barrios S, Zerba E, Picollo MI (2004). Role of enhanced detoxication in a deltamethrin-resistant population of Triatoma infestans (Hemiptera, Reduviidae) from Argentina. Mem Inst Oswaldo Cruz 99: 335-339.

Gregorio EA, Ratcliffe NA (1991). The phenoloxidase system and in vitro interaction of Trypanosoma rangeli with Rhodnius prolixus and Triatoma infestans. Parasite Immunol 13: 551-564.

Grubhoffer L, Hypsa V, Volf P (1997). Lectins (hemagglutinins) in the gut of the important disease vectors. Parasite 4: 203-216.

Guhl F, Pinto N, Aguilera G (2009). Sylvatic triatominae: a new challenge in vector control transmission. Mem Inst Oswaldo Cruz 104(Suppl 1): 71-75.

Guhl F, Vallejo GA (2003). Trypanosoma (Herpetosoma) rangeli Tejera, 1920: an updated review. Mem Inst Oswaldo Cruz 98: 435-442.

Gurgel-Goncalves R, Ferreira JB, Rosa AF, Bar ME, Galvão C (2010). Geometric morphometrics and ecological niche modelling for delimitation of near-sibling triatomine species. Med Vet Entomol 25: 84-93.

Gurtler RE, Diotaiuti L, Kitron U (2008). Commentary: Chagas disease: 100 years since discovery and lessons for the future. Int J Epidemiol 37: 698-701.

Harry M, Galindez I, Cariou ML (1992). Isozyme variability and differentiation between Rhodnius prolixus, $R$. robustus and R. pictipes, vectors of Chagas disease in Venezuela. Med Vet Entomol 6: 37-43.

Harry M, Moreno G, Goyffon M (1993). Isozyme variability in Rhodnius prolixus populations, vectors of Chagas disease in Venezuela. Evolución Biológica 6: 175-194.

Herrera-Aguilar M, Be-Barragán LA, Ramirez-Sierra MJ, Tripet F, Dorn P, Dumonteil E (2009). Identification of a large hybrid zone between sympatric sibling species of Triatoma dimidiata in the Yucatan peninsula, Mexico, and its epidemiological importance. Infect Genet Evol 9: 1345-1351.

Horton AA, Lee Y, Coulibaly CA, Rashbrook VK, Cornel AJ, Lanzaro GC et al. (2010). Identification of three single nucleotide polymorphisms in Anopheles gambiae immune signaling genes that are associated with natural Plasmodium falciparum infection. Malar J 9: 160.

Hypsa V, Tietz DF, Zrzav J, Rego RO, Galvão C, Jurberg J (2002). Phylogeny and biogeography of Triatominae (Hemiptera: Reduviidae): molecular evidence of a New World origin of the Asiatic clade. Mol Phylogenet Evol 23: 447-457.

Jackson Y, Myers C, Diana A, Marti HP, Wolff H, Chappuis F et al. (2009). Congenital transmission of Chagas disease in Latin American immigrants in Switzerland. Emerg Infect Dis 15: 601-603.

Kollien AH, Fechner S, Waniek PJ, Schaub GA (2003). Isolation and characterization of a cDNA encoding for a lysozyme from the gut of the reduviid bug Triatoma infestans. Arch Insect Biochem Physiol 53: 134-145.

Kollien AH, Schaub GA (2000). The development of Trypanosoma cruzi in Triatominae. Parasitol Today 16: 381-387.

Lardeux F, Depickere S, Duchon S, Chavez T (2010). Insecticide resistance of Triatoma infestans (Hemiptera, Reduviidae) vector of Chagas disease in Bolivia. Trop Med Int Health 15: 1037-1048.

Lehmann P, Ordonez R, Ojeda-Baranda R, de Lira JM, Hidalgo-Sosa L, Monroy C et al. (2005). Morphometric analysis of Triatoma dimidiata populations (Reduviidae: Triatominae) from Mexico and Northern Guatemala. Mem Inst Oswaldo Cruz 100: 477-482.

Lent H, Wygodzinsky P (1979). Revision of the Triatominae (Hemiptera, Reduviidae), and their significance as vectors of Chagas' disease. Bull Am Mus Nat Hist 163: 123-520.

Li J, Ribeiro JM, Yan G (2010). Allelic gene structure variations in Anopheles gambiae mosquitoes. PLoS One 5: e10699.

Lopez L, Morales G, Ursic R, Wolff M, Lowenberger C (2003). Isolation and characterization of a novel insect defensin from Rhodnius prolixus, a vector of Chagas disease. Insect Biochem Mol Biol 33: 439-447.

Lopez G, Moreno J (1995). Genetic variability and differentiation between populations of Rhodnius prolixus and R. pallescens, vectors of Chagas' disease in Colombia. Mem Inst Oswaldo Cruz 90: 353-357.

Marcet PL, Mora MS, Cutrera AP, Jones L, Gurtler RE, Kitron U et al. (2008). Genetic structure of Triatoma infestans populations in rural communities of Santiago del Estero, northern Argentina. Infect Genet Evol 8: 835-846.

Marcilla A, Bargues MD, Ramsey JM, Magallon-Gastelum E, Salazar-Schettino PM, AbadjFranch $\mathrm{F}$ et al. (2001). The ITS-2 of the nuclear rDNA as a molecular marker for populations, species, and phylogenetic relationships in Triatominae (Hemiptera: Reduviidae), vectors of Chagas disease. Mol Phylogenet Evol 18: 136-142.

Martinez-Hernandez F, Martinez-Ibarra JA, Catala S, Villalobos G, de la Torre P, Laclette JP et al. (2010). Natural crossbreeding between sympatric species of the Phyllosoma 
complex (Insecta: Hemiptera: Reduviidae) indicate the existence of only one species with morphologic and genetic variations. Am J Trop Med Hyg 82: 74-82.

Martinez-Ibarra JA, Salazar-Schettino PM, Nogueda-Torres B, Vences MO, Tapia-Gonzales JM et al. (2009). Occurrence of hybrids and laboratory evidence of fertility among three species of the Phyllosoma complex (Hemiptera: Reduviidae) in Mexico. Mem Inst Oswaldo Cruz 104: 1125-1131.

Mas-Coma S, Bargues MD (2009). Populations, hybrids and the systematic concepts of species and subspecies in Chagas disease triatomine vectors inferred from nuclear ribosomal and mitochondrial DNA. Acta Trop 110: 112-136.

Megy K, Hammond M, Lawson D, Bruggner RV, Birney E, Collins FH (2009). Genomic resources for invertebrate vectors of human pathogens, and the role of VectorBase. Infect Genet Evol 9: 308-313.

Melgar S, Chavez JJ, Landaverde P, Herrera F, Rodas A, Enriquez E et al. (2007). The number of families of Triatoma dimidiata in a Guatemalan house. Mem Inst Oswaldo Cruz 102: 221-223.

Mello CB, Azambuja P, Garcia ES, Ratcliffe NA (1996). Differential in vitro and in vivo behaviour of three strains of Trypanosoma cruzi in the gut and hemolymph of Rhodnius prolixus. Exp Parasitol 82: 112-121.

Mello CB, Garcia ES, Ratcliffe NA, Azambuja P (1995). Trypanosoma cruzi and Trypanosoma rangeli: interplay with hemolymph components of Rhodnius prolixus. $J$ Invertebr Pathol 65: 261-268.

Mello CB, Nigam Y, Garcia ES, Azambuja P, Newton RP, Ratcliffe NA (1999). Studies of a hemolymph lectin isolated from Rhodnius prolixus and its interaction with Trypanosoma rangeli. Exp Parasitol 91: 289-296.

Menu F, Ginoux M, Rajon E, Lazzari CR, Rabinovich JE (2010). Adaptive developmental delay in Chagas disease vectors: an evolutionary ecology approach. PLoS Negl Trop Dis 4: e691.

Monroy C, Bustamante DM, Pineda S, Rodas A, Castro X, Ayala V et al. (2009). House improvements and community participation in the control of Triatoma dimidiata re-infestation in Jutiapa, Guatemala. Cad Saude Publica 25(Suppl 1): S168-S178.

Monroy C, Rodas A, Mejía M, Tabaru Y (1998). Wall plastering and paints as methods to control vector of Chagas disease in Guatemala. Med Entomol Zool 49: 187-193.

Monteiro FA, Barrett TV, Fitzpatrick S, Cordon-Rosales C, Feliciangeli D, Beard CB (2003). Molecular phylogeography of the Amazonian Chagas disease vectors Rhodnius prolixus and $R$. robustus. Mol Ecol 12: 997-1006.

Monteiro FA, Donnelly MJ, Beard CB, Costa J (2004). Nested clade and phylogeographic analyses of the Chagas disease vector Triatoma brasiliensis in Northeast Brazil. Mol Phylogenet Evol 32: 46-56.

Monteiro FA, Lazoski C, Noireau F, Solé-Cava AM (2002). Allozyme relationships among ten species of Rhodniini, showing paraphyly of Rhodnius including Psammolestes. Med Vet Entomol 16: 83-90.

Monteiro F, Marcet P, Dorn P (2010). Population genetics of triatomines. In: Telleria J, Tibayrenc M (eds). American Trypanosomiasis Chagas Disease, One Hundred Years of Research. Elsevier: Amsterdam. pp 169-208.

Monteiro FA, Perez R, Panzera F, Dujardin JP, Galvao C, Rocha D et al. (1999). Mitochondrial DNA variation of Triatoma infestans populations and its implication on the specific status of T melanosoma. Mem Inst Oswaldo Cruz 94(Suppl 1): 229-238.

Monteiro FA, Wesson DM, Dotson EM, Schofield CJ, Beard CB, Monteiro FA (2000). Phylogeny and molecular taxonomy of the Rhodniini derived from mitochondrial and nuclear DNA sequences. Am J Trop Med Hyg 62: 460-465.

Nei M, Tajima F (1981). Genetic drift and estimation of effective population size. Genetics 98: 625-640.

Noireau F, Flores R, Gutierrez T, Dujardin JP (1997). Detection of sylvatic dark morphs of Triatoma infestans in the Bolivian Chaco. Mem Inst Oswaldo Cruz 92: 583-584.

Noireau F, Gutierrez T, Zegarra M, Flores R, Breniere F, Cardozo L et al. (1998). Cryptic speciation in Triatoma sordida (Hemiptera: Reduviidae) from the Bolivian Chaco. Trop Med Int Health 3: 364-372.

Nouvellet P, Ramirez-Sierra MJ, Dumonteil E, Gourbière S (2011). Effects of genetic factors and infection status on wing morphology of Triatoma dimidiata species complex. Infect Genet Evol 11: 1243-1249.

Núñez JA (1987). Behavior of Triatominae bugs. In: Brenner R, Stoka A (eds). Chagas' Disease Vectors. CRC Press: Boca Raton, FL. pp 1-27.

Obara MT, da Rosa JA, Ceretti Jr W, Urbinatti PR, Quintero LO, Barata JM et al. (2007). A study of the scutellum in eight Chagas disease vector species from genus Triatoma (Hemiptera, Reduviidae) using optical and scanning electron microscopy. Mem Inst Oswaldo Cruz 102: 463-468.

Orihuela PL, Vassena CV, Zerba EN, Picollo MI (2008). Relative contribution of monooxygenase and esterase to pyrethroid resistance in Triatoma infestans (Hemiptera: Reduviidae) from Argentina and Bolivia. J Med Entomol 45: 298-306.

Oscherov EB, Damborsky MP, Bar ME, Avalos G, Alvarez BM, Presman H et al. (2001). Interactions between Triatoma infestans and Triatoma sordida (Hemiptera: Reduviidae) in artificial ecotopes: population growth and age structure. J Med Entomol 38: 214-217.

Oscherov EB, Damborsky MP, Bar ME, Gorla DE (2004). Competition between vectors of Chagas disease, Triatoma infestans and T. sordida: effects on fecundity and mortality. Med Vet Entomol 18: 323-328.

Panzera F, Alvarez F, Sánchez-Rufas J, Pérez R, Suja JA, Scvortzoff E et al. (1992). C-heterochromatin polymorphism in holocentric chromosomes of Triatoma infestans (Hemiptera, Reduviidae). Genome 35: 1068-1074.

Panzera F, Hornos S, Pereira J, Cestau R, Canale D, Diotaiuti L et al. (1997). Genetic variability and geographic differentiation among three species of triatomine bugs (Hemiptera-Reduviidae). Am J Trop Med Hyg 57: 732-739.
Panzera F, Dujardin JP, Nicolini P, Caraccio MN, Rose V, Tellez T et al. (2004). Genomic changes of Chagas disease vector, South America. Emerg Infect Dis 10: 438-446.

Panzera F, Ferrandis I, Ramsey J, Ordonez R, Salazar-Schettino PM, Cabrera M et al. (2006). Chromosomal variation and genome size support existence of cryptic species of Triatoma dimidiata with different epidemiological importance as Chagas disease vectors. Trop Med Int Health 11: 1092-1103.

Panzera F, Perez R, Panzera Y, Ferrandis I, Ferreiro MJ, Calleros L (2010). Cytogenetics and genome evolution in the subfamily Triatominae (Hemiptera, Reduviidae). Cytogenet Genome Res 128: 77-87.

Patterson JS, Gaunt MW (2010). Phylogenetic multi-locus codon models and molecular clocks reveal the monophyly of haematophagous reduviid bugs and their evolution at the formation of South America. Mol Phylogenet Evol 56: 608-621.

Pavan MG, Monteiro FA (2007). A multiplex PCR assay that separates Rhodnius prolixus from members of the Rhodnius robustus cryptic species complex (Hemiptera: Reduviidae). Trop Med Int Health 12: 751-758.

Payne F (1909). Some new types of chromosome distribution and their relation to sex. Biol Bull 16: 119-166.

Pereira MEA, Andrade AFB, Ribeiro JMC (1981). Lectins of distinct specificity in Rhodnius prolixus interact selectively with Trypanosoma cruzi. Science 211: 597-600.

Pereira MH, Gontijo NF, Guarneri AA, Santanna MR, Diotaiuti L (2006). Competitive displacement in Triatominae: the Triatoma infestans success. Trends Parasitol 22: 516-520.

Perez R, Panzera Y, Scafiezzo S, Mazzella MC, Panzera F, Dujardin JP et al. (1992). Cytogenetics as a tool for triatomine species distinction (Hemiptera-Reduviidae). Mem Inst Oswaldo Cruz 87: 353-361.

Perez R, Hernandez M, Quintero O, Scvortzoff E., Canale D, Mendez L et al. (2005). Cytogenetic analysis of experimental hybrids in species of Triatominae (HemipteraReduviidae). Genetica 125: 261-270.

Perez de Rosas AR, Segura EL, Fichera L, Garcia BA (2008). Macrogeographic and microgeographic genetic structure of the Chagas' disease vector Triatoma infestans (Hemiptera: Reduviidae) from Catamarca, Argentina. Genetica 133: 247-260.

Perez de Rosas AR, Segura EL, Garcia BA (2007). Microsatellite analysis of genetic structure in natural Triatoma infestans (Hemiptera: Reduviidae) populations from Argentina: its implication in assessing the effectiveness of Chagas' disease vector control programmes. Mol Ecol 16: 1401-1412.

Perez de Rosas AR, Segura EL, Garcia BA (2011). Molecular phylogeography of the Chagas' disease vector Triatoma infestans in Argentina. Heredity 107: 71-79.

Piccinali RV, Marcet PL, Noireau F, Kitron U, Gürtler RE, Dotson EM (2009). Molecular population genetics and phylogeography of the Chagas disease vector Triatoma infestans in South America. J Med Entomol 46: 796-809.

Picollo MI, Vassena C, Santo Orihuela P, Barrios S, Zaidemberg M, Zerba E (2005). High resistance to pyrethroid insecticides associated with ineffective field treatments in Triatoma infestans (Hemiptera: Reduviidae) from Northern Argentina. J Med Entomol 42: 637-642.

Pizarro JC, Gilligan LM, Stevens L (2008). Microsatellites reveal a high population structure in Triatoma infestans from Chuquisaca, Bolivia. PLoS Negl Trop Dis 2: e202.

Pulido XC, Pérez G, Vallejo GA (2008). Preliminary characterization of a Rhodnius prolixus hemolymph trypanolytic protein, this being a determinant of Trypanosoma rangeli $\mathrm{KP} 1(+)$ and $\mathrm{KP} 1(-)$ subpopulations' vectorial ability. Mem Inst Oswaldo Cruz 103: 172-179.

Ramirez CJ, Jaramillo CA, del Pilar Delgado M, Pinto NA, Aguilera G, Guhl F: Genetic structure of sylvatic, peridomestic and domestic populations of Triatoma dimidiata (Hemiptera: Reduviidae) from an endemic zone of Boyaca, Colombia. Acta Trop 93: 23-29.

Ratcliffe NA, Nigam Y, Mello CB, Garcia ES, Azambuja P (1996). Trypanosoma cruzi and erythrocyte agglutinins: a comparative study of occurrence and properties in the gut and hemolymph of Rhodnius prolixus. Exp Parasitol 83: 83-93.

Richer W, Kengne P, Cortez MR, Perrineau MM, Cohuet A, Fontenille D et al. (2007). Active dispersal by wild Triatoma infestans in the Bolivian Andes. Trop Med Int Health 12: 759-764.

Sacks D, Kamhawi S (2001). Molecular aspects of parasite-vector and vector-host interactions in Leishmaniasis. Annu Rev Microbiol 55: 453-483.

Schaub GA (1988). Developmental time and mortality of larvae of Triatoma infestans infected with Trypanosoma cruzi. Trans R Soc Trop Med Hyg 82: 94-96.

Schaub GA (1989). Does Trypanosoma cruzi stress its vectors? Parasitol Today 5: $185-188$.

Schaub GA (1994). Pathogenicity of trypanosomatids on insects. Parasitol Today 10: 463-468.

Schaub GA (2006). Parasitogenic alterations of vector behaviour. Int J Med Microbiol 296(Supp1 40): 37-40.

Schaub GA, Lösch P (1989). Parasite/host-interrelationships of the trypanosomatids Trypanosoma cruzi and Blastocrithidia triatomae and the reduviid bug Triatoma infestans: influence of starvation of the bug. Ann Trop Med Parasitol 83: 215-223.

Schofield CJ (2000). Trypanosoma cruzi-The vector-parasite paradox. Mem Inst Oswaldo Cruz 95: 535-544.

Schofield CJ, Dias JC (1999). The Southern Cone initiative against Chagas disease. Adv Parasitol 42: 1-27.

Schofield CJ, Diotaiuti L, Dujardin JP (1999). The process of domestication in Triatominae. Mem Inst Oswaldo Cruz 94(Supp1 1): 375-378.

Schofield CJ, Jannin J, Salvatella R (2006). The future of Chagas disease control. Trends Parasitol 22: 583-588.

Schofield CJ, Galvão C (2009). Classification, evolution, and species groups within the Triatominae. Acta Trop 110: 88-100. 
Silva MBA, Barbosa HS, Galvão C, Jurberg J, Carcavallo RU (2003). Comparative study of the stridulatory sulcus, buccula and rostrum of the nymphs of Triatoma guazu and Triatoma jurbergi by scanning electron microscopy (Hemiptera, Reduviidae). Mem Instit Oswaldo Cruz 98: 335-344.

Silva MBA, Barbosa HS, Jurberg J, Galvão C, Carcavallo RU (2002). Comparative ultrastructural analysis of the antennae of Triatoma guazu and Triatoma jurbergi (Hemiptera: Reduviidae) during the nymphal stage development. J Med Entomol 39: 705-715.

Slimi R, El Yacoubi S, Dumonteil E, Gourbière S (2009). A cellular automata model for Chagas disease. Appl Math Model 33: 1072-1085.

Tamay-Segovia P, Alejandre-Aguilar R, Martínez F, Villalobos G, de la Serna FJ, de la Torre P et al. (2008). Two Triatoma dimidiata clades (Chagas disease vector) associated with different habitats in southern Mexico and Central America. Am J Trop Med Hyg 78: $472-478$.

Tartarotti E, Azeredo-Oliveira MTV, Ceron CR (2006). Phylogenetic approach to the study of triatomines (Triatominae, Heteroptera). Braz J Biol 66: 703-707.

Toloza AC, Germano M, Cueto GM, Vassena C, Zerba E, Picollo MI (2008). Differential patterns of insecticide resistance in eggs and first instars of Triatoma infestans (Hemiptera: Reduviidae) from Argentina and Bolivia. J Med Entomol 45: 421-426.

Torres-Perez F, Acuna-Retamar M, Cook JA, Bacigalupo A, Garcia A, Cattan PE (2011). Statistical phylogeography of Chagas disease vector Triatoma infestans: testing biogeographic hypotheses of dispersal. Infect Genet Evol 11: 167-174.

Ursic-Bedoya RJ, Lowenberger CA (2007). Rhodnius prolixus: identification of immunerelated genes upregulated in response to pathogens and parasites using suppressive subtractive hybridization. Dev Comp Immunol 31: 109-120.

Ursic-Bedoya RJ, Nazzaria H, Trianab O, Wolffb M, Lowenbergera C (2008). Identification and characterization of two novel lysozymes from Rhodnius prolixus, a vector of Chagas disease. J Insect Physiol 54: 593-603.

Vallejo GA, Guhl F, Carranza JC, Lozano LE, Sánchez JL, Jaramillo JC et al. (2002). kDNA markers define two major Trypanosoma rangeli lineages in Latin-America. Acta Trop 81: 77-82.

Vallejo GA, Guhl F, Carranza JC, Moreno J, Triana O, Grisard EC (2003). Parity between kinetoplast DNA and mini-exon gene sequences supports either clonal evolution or speciation in Trypanosoma rangeli strains isolated from Rhodnius colombiensis, $R$. pallescens and R. prolixus in Colombia. Infect Genet Evol 3: 39-45.
Vallejo GA, Guhl F, Schaub GA (2009). Triatominae-Trypanosoma cruzi/T. rangeli: vector-parasite interactions. Acta Trop 110: 137-147.

Vargas LG, Zeledon R (1985). Effect of fasting on Trypanosoma cruzi infection in Triatoma dimidiata (Hemiptera: Reduviidae). J Med Entomol 22: 683.

Villela MM, Souza JB, Mello VP, Azeredo BV, Dias JC (2005). Entomological surveillance for Chagas disease in the mid-western region of Minas Gerais State, Brazil, from 2000 to 2003. Cad Saude Publica 21: 878-886.

Waniek PJ, Castro HC, Sathler PC, Miceli L, Jansen AM, Araújo CA (2009). Two novel defensin-encoding genes of the Chagas disease vector Triatoma brasiliensis (Reduviidae, Triatominae): gene expression and peptide-structure modeling. J Insect Physiol 55: 840-848.

Waniek PJ, Jansen AM, Araújo CAC (2011). Trypanosoma cruzi infection modulates the expression of Triatoma brasiliensis def1 in the midgut. Vector Borne Zoonotic Dis 11: 845-847.

Weirauch C (2008). Cladistic analysis of Reduviidae (Heteroptera: Cimicomorpha) based on morphological characters. Syst Entomol 33: 229-274.

Weirauch C, Munro JB (2009). Molecular phylogeny of the assassin bugs (Hemiptera: Reduviidae), based on mitochondrial and nuclear ribosomal genes. Mol Phylogenet Evol 53: 287-299.

Whitten MMA, Mello CB, Gomes SAO, Nigam Y, Azambuja P, Garcia ES et al. (2001). Role of superoxide and reactive nitrogen intermediates in Rhodnius prolixus (Reduviidae)/ Trypanosoma rangeli interactions. Exp Parasitol 98: 44-57.

Whitten M, Sun F, Tew I, Schaub GA, Soukou C, Nappis A et al. (2007). Differential modulation of Rhodnius prolixus nitric oxide activities following challenge with Trypanosoma rangeli, T. cruzi and bacterial cell wall components. Insect Biochem $\mathrm{Mol}$ Biol 37: 440-452.

WHO (2007). Reporte sobre la enfermedad de Chagas. 17-20 de abril de 2005, Actualizado en Julio de 2007, Buenos Aires, Argentina. WHO: Geneva. p 96.

Wright S (1943). Isolation by distance. Genetics 28: 114-138.

Zeledón R (1981). El Triatoma dimidiata (Latreille, 1811) y su relación con la enfermedad de Chagas. Editorial Universidad Estatal a Distancia, Costa Rica. p 146.

Zeledon R (1987). Life cycle of Trypanosoma cruzi in the insect vector. In: Brenner RR, Stoka AM (eds). Chagas Disease Vectors (Anatomical and Physiological Aspects). CRC Press: Boca Raton, Florida. pp 59-75.

Zu Dohna H, Cecere MC, Gurtler RE, Kitron U, Cohen JE (2007). Re-establishment of local populations of vectors of Chagas disease after insecticide spraying. J App/ Ecol 44: 220-227. 